\title{
Game Analysis of Endowment Insurance Collection and Supervision Behavior under the Background of Price Reduction
}

\author{
Jin Zhang \\ Central University of Finance and Economics
}

\begin{abstract}
The Central government issued several consecutive articles stressing the need to reduce the contribution rate of endowment insurance and adjust the base of social security contributions. However, can we effectively improve the compliance rate of endowment insurance, and thus increase the actual collection income of endowment insurance through the reform of the fee reduction? What changes will be made to the behavioral decision-making methods among the various subjects, and will it affect the income from the collection of pensions? What kind of supervision is adopted by the central and local governments to promote the increase in the collection of endowment insurance? Based on these problems, this paper adopts the principal-agent game and the three-party evolutionary game model under non-completely symmetric information, analyzes the behavioral decisions of each subject in the process of collection after the fee reduction, and analyzes the influencing factors of dynamic stability and equilibrium. Analysis, and finally, in the context of the endowment insurance fee reduction, the action plan that can effectively increase the income of the endowment insurance collection. The empirical results show that the contribution rate and contribution base of endowment insurance are inversely related to the intensity of local endowment insurance collection, and the reduction of fees can effectively promote the enthusiasm of local governments for collection. When the burden of endowment insurance contributions declines, the enthusiasm of corporate payment has also increased. At the same time, improve the overall level of pensions, promote the openness and transparency of endowment insurance contributions, and strengthen the reward and punishment mechanism in the process of collecting endowment insurance premiums, which can effectively increase the income from endowment insurance collection.
\end{abstract}

Key words : Reform of fee reduction; Endowment insurance collection; Evolutionary game

\section{INTRODUCTION}

Collection and payment are the basis for guaranteeing the operation of endowment insurance system (Liu, 2011). Can the goal of full collection and payment of endowment insurance be achieved through the reduction of the policy contribution rate and the contribution base? Is there any room for further reductions in the endowment insurance contribution rate and contribution base? What kind of regulatory action the government should take to ensure the full collection of endowment insurance, while simultaneously reducing the burden the burden of enterprise contributions and increasing the sustainability of the endowment insurance system is an important issue worthy of further study.

In March 2019, the State Council of China released the report on the work of the government, in which emphasized that in order to substantively reduce enterprise contributions to social insurance schemes and boost the market dynamics, the government will keep lower the share borne by employers for urban workers' basic aged-care insurance. In April 2019, the State Council issued the Comprehensive Plan for Reducing Social Insurance Contribution Rates, which ushered in an unprecedented change in the basic endowment insurance payment 
regulations for urban workers. The collection rate by employers for urban workers' basic agedcare insurance has plunged sharply and localities may cut contributions down to 16 percent. At the same time, the payment base of basic endowment insurance has been adjusted for the first time since the establishment of the system. The contribution base of average salary of employees in non-private units is adjusted to the average salary of employees in full-caliber urban units. There is no doubt that in the context of a policy to optimize the business environment, the basic endowment insurance fee reduction reform is of great significance to reduce the burden of corporate payment, stimulate market vitality, stabilize the employment environment, and improve national competitiveness (Qi, 2019). However, considering that the endowment insurance fee reduction reform has caused a huge impact on China's current endowment insurance income structure, how to ensure the full collection of endowment insurance while reducing the cost should also be a key concern on the premise of maintaining the same pension treatment, keeping the balance of endowment insurance fund as well as not increasing the financial burden.

The existing research focuses on the analysis of whether endowment insurance has room for fee reduction by constructing an actuarial model of endowment insurance, whether the reduction in contribution rate will cause a gap in the income and expenditure of endowment insurance funds, and the impact of fee reductions on the sustainability of endowment insurance. The results of the study show that the reduction of endowment insurance is feasible. This is due to the fact that before the fee reduction reform, there was a low actual contribution rate during the endowment insurance payment process (Yang et al., 2018) and the payment base was "unreal" (Feng, 2013; Zheng, 2018), lowering the contribution rate and payment base can increase payment incentives and promote voluntary contributions by enterprises and workers. The fee reduction reform can increase the collection income of endowment insurance fund in the short term, ensure that the two goals of reducing endowment insurance contributions and fund sustainability can be achieved simultaneously (Zeng et al., 2019); however, in the long run, it is possible to widen the gap between the income and expenditure of endowment insurance fund (Chen, 2017), only by adopted relevant policies and measures such as increasing the transfer of state capital and increasing fiscal subsidies to maintain the sustainability of the endowment insurance fund.

In fact, during the endowment insurance collection process, due to the low overall level of endowment insurance, the government and enterprises are still in a non-cooperative game state with asymmetric information (Zheng, 2016), and enterprises and workers have insufficient payment incentives. So, after the implementation of the nationwide fee reduction policy, will it be feasible to increase the compliance rate of endowment insurance, expand the coverage of endowment insurance, and thereby increase the income from endowment insurance collection? After the fee reduction, how will the moral hazards of the various entities involved in the endowment insurance payment process affect the implementation of the policy? How will the central and local governments respond to the problem of insufficient payment that may still exist? The research in this article will focus on the above issues.

During the endowment insurance collection process, the central government, local governments, enterprises, and workers as stakeholders will choose behaviors based on the goal of maximizing their own interests. In the decision-making process, it is difficult for various stakeholder groups to meet the complete rational hypothesis with incomplete information, and a static Nash equilibrium strategy will not be achieved. The evolutionary game model can effectively describe the stable equilibrium strategy that the two sides of the game make multiple choices gradually under the condition of limited rationality. Therefore, this article will use a multi-agent evolutionary game method to analyze the behavior of the four stakeholders 
including the central government, local government, enterprises, and workers after fee reductions, and explore how to ensure the full collection of endowment insurance and how to resolve the contradictions between the various entities under the background of endowment insurance fee reduction, thereby improving the efficiency of government supervision. The subsequent chapters of this article are arranged as follows. The first part raises questions, the second part reviews relevant literature, the third part constructs the game model, the fourth part analyzes and discusses the model, and the fifth part summarizes the research content.

\section{LITERATURE REVIEW}

The collection of endowment insurance is not only closely related to the sustainable development of the system itself, but also related to the payment burden of enterprises and individuals, which affects the speed of economic development. The research on the issue of endowment insurance collection in academic circles mainly focuses on two aspects, one is to study the level of endowment insurance payment, and the other is to focus on the supervision of the endowment insurance collection process.

For the research on the level of endowment insurance payment, the focus is on the insufficient actual collection income during the endowment insurance payment process (Feng, 2013), specifically, company's behavior of evading arrears (Yang, 2010) lead to the actual payment of endowment insurance far lower than the policy payment level (Yang et al., 2018). Some scholars analyzed the actual level of endowment insurance contributions. Feng (2013) calculated the actual payment level of endowment insurance contributions of industrial manufacturing enterprises in the four provinces of Jiangsu, Zhejiang, Fujian, and Guangdong from 2005 to 2007. The average value of the actual contribution rate of endowment insurance and medical insurance was only 10.82\%. Wang et al. (2017) used Guotai'an Database's corporate report data and CFPS (China Urban Household Survey) data to construct a simultaneous equation, and calculated the actual payment level of enterprise's social insurance is only 13.5\%. Yang et al. (2018) estimated that the social insurance collection level in 31 provinces (municipalities and districts) from 2010 to 2015 was about $25 \%-27 \%$, and the actual collection level in the eastern region was lower than that in the central and western regions. Cheng and Deng (2019) used data of Chinese Enterprise-Employee Matching Survey (CEES) in 2015, and through the OLS regression and Probit model to find that the actual contribution rate of Chinese corporate social insurance in 2013-2015 was 16\%. about. Other scholars have analyzed the causes of insufficient payment of endowment insurance costs, mainly due to the high level of policy contributions, which has caused adverse incentives to enterprises, resulting in low compliance rates for enterprises (Zhao et al., 2015; Zheng, 2019). $\mathrm{Hu}$ and Jing (2014) constructed asymmetric evolutionary game models for the payment of endowment insurance premiums by enterprises and individuals, and concluded that enterprises play a leading role in paying endowment insurance premiums in full. Make decisions on your own income and payment burden. Zhao et al. (2015) used CFPS data from 2002-2009 and data from industrial enterprises above designated size in 2004-2007 to analyze that under the high policy contribution rate, the actual payment level of enterprises has significantly decreased; especially high education level, high positions, senior Employees with state-owned collective economies, as well as small and medium-sized enterprises and private enterprises, have a stronger tendency to underpay. In cities with a high proportion of floating population in the total population, the actual level of endowment insurance collection is lower.

Regarding the research on the supervision of the endowment insurance collection process, the first is the setting of the endowment insurance collection management organization. Enoff (2011) proposed that there are 7 important factors to ensure the full payment of endowment 
insurance. Most importantly, Bailey and Turner (2001) and McGillivray (1998) proposed that combining the social insurance department and the tax collection department is conducive to the full collection of endowment insurance. Liu (2011) pointed out that in the endowment insurance fee collection system in China, a dual taxation structure has been formed in which both local tax agencies and social insurance agencies are involved. Specifically, it includes three collection management modes: independent collection by the social security agency, social security approval, tax collection, and full tax collection (Wang et al., 2014). Tine Stanovnik et al. (2015) analyzed the endowment insurance collection management model in Poland, Croatia, and Slovenia, and found that the trend of public endowment insurance collection and management is to reduce the position of the social insurance sector in the endowment insurance collection process. Peng et al. (2015) reflected the collection effect of social insurance premiums by constructing 31 provinces (autonomous regions and municipalities) in the full collection rate and expansion rate indicators from 2002 to 2011, and analyzed the collection effect of different collection entities Impact. The results show that the choice of the collection subject has a significant impact on the full collection rate. The collection by the social security agency is generally better than the collection by the local tax authority. On July 20, 2018, the "National Tax Land Tax Collection and Management System Reform Plan" determined that China gradually transitioned to a national tax collection and management model. The second is the government's supervision of endowment insurance collection. Government supervision has an important effect on whether endowment insurance is fully collected (Jiang et al., 2017). However, from the perspective of local governments, scholars have proposed that under the background of the fiscal decentralization system, local governments have a moral-to-bottom moral hazard in endowment insurance collection (Peng, Yue, etc., 2018). In order to promote local economic growth, Tend to pursue lower workers costs, incentive distortion and slack in the collection of endowment insurance (Peng, 2010), induce local governments to actively reduce the actual contribution rate of endowment insurance (Gillion et al., 2000), or it may happen Local governments, enterprises, and the masses also conspired to evade fees (Duan, 2015). From the perspective of the central government, scholars have proposed that in the context of the provincial-level co-ordination of the endowment insurance, the central government's political rights mainly play a role in determining the institutional framework. In the process of actual collection, due to excessive decentralization, the local supervision is insufficient; In order to maintain the prestige among the masses and maintain the operation of the endowment insurance system, the central government has a lot of local financial subsidies, which is likely to create a situation of local overdependence on the central government (Zhao, 2010; Meng, 2014).

In the existing research, in view of the collection and supervision of endowment insurance, the main analysis of the actual level of contributions and the reasons for the low level of contributions; in the analysis of the impact of different collection agencies on the collection and the local government's The main regulatory situation is insufficient consideration of fee reductions. The academic community's research on the reduction of endowment insurance has focused on the reduction of endowment insurance. Some scholars have anticipated the reduction of endowment insurance contribution rate (Zeng et al., 2017; Chen, 2017; Zhang et al., 2017; Li et al., 2018; Zeng et al., 2018) and the optimal contribution rate (Yang, 2017; Yang, 2018), and calculated the change in parameters after the fee reduction to balance the endowment insurance revenue and expenditure (Zeng, 2019; Wang et al., 2019) and economic growth ( Hong et al., 2017). However, in the context of endowment insurance cost reduction reforms, actuarial forecasting methods have made idealized assumptions about the behavior of various entities in the collection process. In actually, after the reform of pension contribution rates and payment bases, the behavior choices of various payment entities are diverse., And the process requires multiple action decisions to gradually reach equilibrium. Although some 
scholars also used game methods to analyze the behavior of evading the arrears of enterprises before the fee reduction reform (Hu, Jing Peng, 2014; Duan, 2015; Jiang, etc., 2017), after the fee reduction, each subject will be based on policy changes. Changes will also occur in decisionmaking. Therefore, this article will assume incomplete rationality, construct an evolutionary game model among multiple subjects, and analyze the collection and supervision of endowment insurance after fee reduction.

\section{MODEL CONSTRUCTION}

The application of the game model in the collection and supervision of government fees is gradually increasing. Meng Rongfang (2014) analyzed the interest-related game relationships between the local government and the central government, enterprises, and workers during the collection of endowment insurance costs; $\operatorname{Li}(2019)$ The cooperative game-bargaining model is used to analyze the game equilibrium of the collective selection of the four stakeholder groups, namely the local government, the social insurance premium collection department, the enterprise, and the workers, during the determination of the social security payment base. Ouyang and Zhou (2019) used evolutionary game methods to construct a threeparty game model including government, enterprises, and workers, and analyzed the tax evasion of enterprises. Peng et al. (2019) considered the merger of national and local tax institutions and the Internet background, and constructed a three-stage game model to study the behavior of tax collection subjects. After the endowment insurance collection agency changed from the social security department to the tax department, the government and enterprises have certain similarities in the collection behavior of endowment insurance costs and the collection behavior of tax collection. feasibility.

With reference to the settings of Meng (2014) and Li (2019), this paper argues that due to regional differences and income distribution, the main insurance group payment process involves four main interest groups, namely the central government, local governments, enterprises and workers. After the implementation of the fee reduction policy, each subject played a pair of games during the payment process and eventually stabilized and balanced. At the same time, the reputation effect and punitive effect were introduced into government decision-making. In summary, this study sets the evolutionary game relationship of the behavioral relationship of various subjects in the process of endowment insurance premium payment after the fee reduction reform as follows.

Fig. 1 Game relationship between various entities in the endowment insurance collection

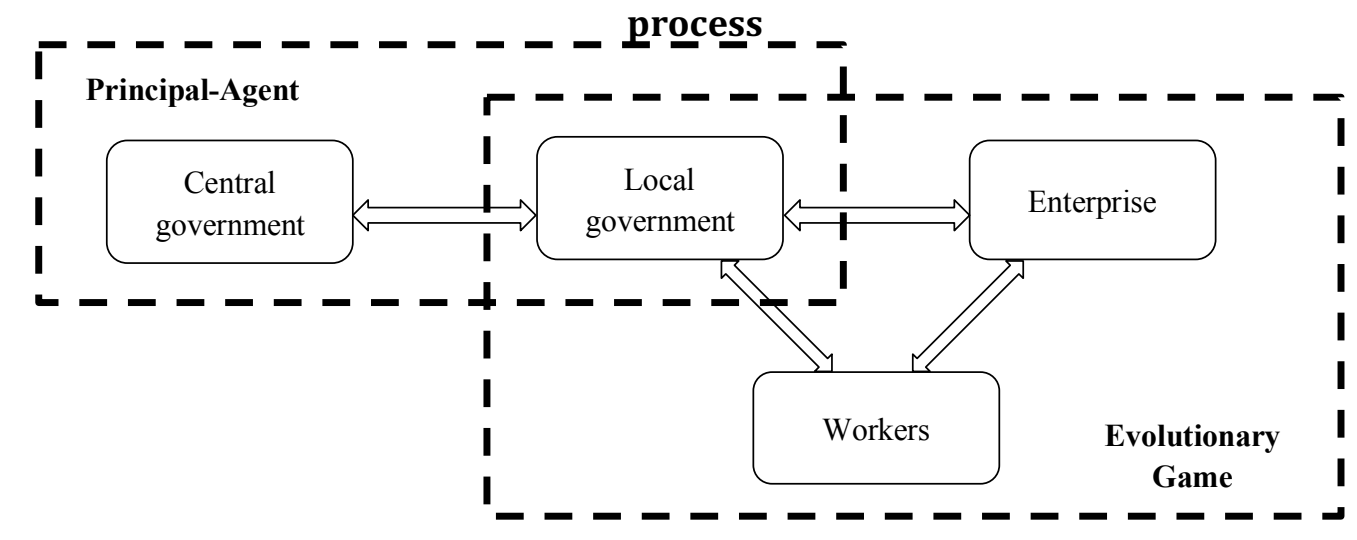

Under the national pension adjustment model, the central government and local governments have information that is not completely symmetrical in the process of collecting endowment insurance. The central government stipulates the level of endowment insurance contributions, and the local government collects endowment insurance premiums based on documents issued by the central government in combination with local actual conditions., Forming a 
similar principal-agent relationship. The income collected by the central government for endowment insurance is learned from the data reported by the local government. It does not directly participate in the collection of endowment insurance for the local government. The local government has more specific information in the actual collection process, and collects information with enterprises and workers in the collection process. There are actual interestrelated relationships in the process, and each subject continuously adjusts its own strategy throughout the process, and finally reaches a relatively stable equilibrium state. Therefore, we construct an evolutionary game model to analyze the equilibrium of local governments, enterprises, and workers in the process of collecting endowment insurance. Finally, combining the game relationship between the central government and local governments, a summary analysis of the game of the four main bodies on the collection of endowment insurance is made.

\section{The game between central and local government}

The central government and local governments have different objective functions according to their own interest preferences in the process of collecting endowment insurance. According to the "Social Insurance Law of the People's Republic of China", the central government department monitors the income, expenditure, management, and investment and operation of social insurance funds in accordance with the law, formulates the level of endowment insurance policy contributions, and pursues maximum global revenue (Chen \& Wang, 2017). Local governments specifically implement the collection and distribution of endowment insurance locally, and are more inclined to maximize their own revenue. Due to the competition between local governments in the development of GDP (Zhou, 2009), sometimes in order to pursue local economic development, the local government has inadequate implementation of policies in collecting endowment insurance costs, and the management standards are not strict, leading to a base for endowment insurance contributions. Problems such as misrepresentation, falsely high contribution rates, and evasion of fees by enterprises. According to the state council's notice on Establishing a central adjustment system for enterprise employees' basic endowment insurance funds, the central government implements a pension adjustment policy for provinces that have realized provincial-level unified pension planning. The central and local governments In terms of insurance collection, a principal-agent relationship has been formed. The local government has an information advantage in the process of collection, and there is an incentive to hide its true actions. The central government has difficulty in grasping all the information of the locality. Therefore, the two sides start a game based on the background of non-complete symmetrical information. In the case of fee reduction and fee adjustment bases, in order to ensure the sustainable development of the endowment insurance system, the central government must prevent the actual collection of endowment insurance from showing a significant downward trend. It is necessary to encourage local governments to strengthen the management of endowment insurance collection so that the local government's decision-making is adjusted in a direction that is conducive to the central government.

\section{Model parameter setting and assumption}

In the model of the central and local government, referring to the principal-agent theory mechanism, the hypotheses are constructed as following.

Hypothesis 1: In the context of reforms in reducing contribution rates and payment bases, both the central government and local governments meet the rational economic person assumption and each chooses the optimal strategy based on the objective function under the condition of maximizing their own revenue.

Hypothesis 2: The level of endowment insurance collection in the model is reported by the local government to the central government. As the principle, central government cannot directly observe the actual collection intensity of endowment insurance by the local 
government, and it is difficult to obtain accurate information from third-party regulatory channels, but the local government have a clear understanding of the actual collection level of endowment insurance.

Hypothesis 3: The central adjustment system is a transitional system of national overall planning of endowment insurance, and the adjustment intensity may continue to change in the future. Therefore, we assume that the upward adjustment coefficient of endowment insurance is not fixed, and the central government has the right to decide the upper adjustment ratio. We assume that the central adjustment coefficient of pension in a given year is $\beta, 0<\beta<1$ 。

Hypothesis 4: The specific settings for each variable are as follows. Assume that the total collection of endowment insurance in a certain year is $Y$, where $Y=\sum Y_{i}, Y_{i}$ represents the endowment insurance fee collected by a local government indicates by $i$. There is a positive correlation between $Y_{i}$ and the endowment insurance payment rate and payment base stipulated by the local government as well as the local tax collection intensity, and the correlation coefficient is $\alpha$. The policy payment rate stipulated by a local government in that year is expressed by $r_{i}$, and the payment base is the average salary of the employees in the previous year, which is expressed by $W_{i}$. The local government collection intensity is expressed by $\phi_{i}$, collection intensity refers to the actual payment level in endowment insurance collection, including the actual number of people who pay and the ratio of the actual payment rate to the policy payment rate. To simplify the calculation, no specific value is used.

Set $Y_{i}=\alpha r_{i} W_{i} \phi_{i}^{2}$, meet $0<\alpha<1, r_{i}>0, W_{i}>0, \phi_{i}>0$.

Local governments need to pay for handling and supervision costs during the collection of endowment insurance premiums, and they increase with the intensity of the collection. But the government needs to measure financial expenditure arrangements during collection. The cost paid is not infinite. It reaches a peak at some point, so it is assumed that the cost to be paid by the local government satisfies $C_{i}=\xi \ln \phi_{i}$. Under the policy of fee reduction, the local government's collection of endowment insurance will help strengthen the reputation of central government among the masses. The gain of reputation effect is positively related to the intensity of local government collection intensity, expressed as $R E_{i}=\tau \ln \phi_{i}$. According to the notice of Administrative Measures on the Funds for the Management of Basic Endowment Insurance for Employees of Central Finance Enterprises issued by the ministry of finance and the ministry of human resources and social security, the strength of central government transfer payments to local governments is related to the effectiveness of local collections ${ }^{1}$. The performance of the work is the reputation effect brought by the local collection to the central government, that is, the transfer payment from the central government to the local government is set to $T R_{i}=\varsigma_{i} R E_{i}$.

During this fee reduction policy, because the payment rates and payment bases of some provinces are already lower than the current policy oriented level, and the payment rates need

\footnotetext{
1 Because this article focuses on the impact of local collections on collected income, this article temporarily ignores the differences in regional pension income and expenditure gaps, maintenance rates, and fiscal transfer payment differences that the central government needs to consider when making local transfer payments.
} 
to be gradually increased, so the central government implemented different subsidies for these provinces $E T_{i}, E T_{i} \geq 0$. The local government has a lower limit of expected fees in the collection of endowment insurance, that is, to maintain the balance of the endowment insurance fund, it is necessary to keep the collection income level at least $B_{i}$.

\section{Model construction and analysis}

According to the above parameter settings, it can be obtained that the games of the central government and local governments in the endowment insurance collection process should respectively satisfy the following objective functions,

The maximization function of central government revenue is as follows:

$$
\begin{gathered}
\max \left[\sum \beta Y_{i}-\sum T R_{i}-\sum E T_{i}+\sum R E_{i}\right] \\
\text { s.t. }(1-\beta) Y_{i}+T R_{i}+E T_{i}-C_{i} \geq B_{i}
\end{gathered}
$$

Under the background of reducing the endowment insurance contribution rate and adjusting the contribution base, local government collection should reduce the burden on enterprises while maintaining the goal of sustainable operation of the endowment insurance fund. Assume $Q$ represents the level of endowment insurance contributions before the implementation of the policy, Y indicates that the level of endowment insurance contributions of the enterprise after

the fee reduction, then $Q-Y_{i}>0$ should be meet. Therefore, the revenue maximization function of local government is expressed as follows.

$$
\begin{gathered}
\max \left[(1-\beta) Y_{i}+T R_{i}+E T_{i}-C_{i}\right] \\
\text { s.t. } Q-Y_{i}>0
\end{gathered}
$$

If substituted into the parameter settings, the Lagrange function of local government revenue maximization can be obtained as follows.

$$
L_{D}=(1-\beta) \alpha r_{i} W_{i} \phi_{i}^{2}+\varsigma_{i} \tau \ln \phi_{i}+E T_{i}-\xi \ln \phi_{i}-\lambda\left(\alpha r_{i} W_{i} \phi_{i}^{2}-Q\right)
$$

According to the Kuhn-Tucker condition, solving the equation (5), the optimal solution for the local government's collection intensity can be obtained as:

$$
\phi_{i}=\left(\frac{\xi-\varsigma_{i} \tau}{2(1-\beta-\lambda) \alpha r_{i} W_{i}}\right)^{1 / 2}
$$

Then the Lagrange function of the central government in the collection of endowment insurance is ( $S_{i}$ represents the slack variable in the function):

$$
L_{z}=\left[\sum \beta Y_{i}-\sum T R_{i}-\sum E T_{i}+\sum R E_{i}\right]-\lambda\left[(1-\beta) Y_{i}+T R_{i}+E T_{i}-C_{i}-S_{i}\right]
$$

According to the kuhn-tucker condition, $\frac{\partial L_{Z}}{\partial \beta}=0$ can be obtained by solving equation (7), namely:

$\sum Y_{i}-\sum \frac{\beta\left(\xi-\varsigma_{i} \tau\right)}{2(1-\beta-\lambda)^{2}}+\sum \frac{\tau\left(1-\varsigma_{i}\right)}{2(1-\beta-\lambda)}-\lambda Y_{i}+\frac{\lambda(1-\beta)\left(\xi-\varsigma_{i} \tau\right)}{2(1-\beta-\lambda)^{2}}-\frac{\lambda\left(\varsigma_{i}-\xi\right)}{2(1-\beta-\lambda)}=0$ 
Equation (8) shows that the coefficient that affects the intensity of local government collections also plays an important role in the revenue of the central government. At the same time, the central government's transfer payments to local governments are also affected by the above factors. From the results of the above calculations, it can be found that

$$
(1-\beta) Y_{i}+T R_{i}+E T_{i}-C_{i}-S_{i}=B_{i}, \quad T R_{i}=\varsigma_{i} R E_{i}=\varsigma_{i} \tau \ln \phi_{i}, \quad \phi_{i}=\left(\frac{\xi-\varsigma_{i} \tau}{2(1-\beta-\lambda) \alpha r_{i} W_{i}}\right)^{1 / 2} .
$$

So we can deduced that

$$
T R_{i}=B_{i}-(1-\beta) Y_{i}+T R_{i}+E T_{i}-C_{i}-S_{i}=\varsigma_{i} \tau \ln \phi_{i}=\frac{\varsigma_{i} \tau}{2} \ln \frac{\xi-\varsigma_{i} \tau}{2(1-\beta-\lambda) \alpha r_{i} W_{i}}
$$

Meanwhile, for equation (6), we can get the first and the second order partial derivatives about $\beta$ respectively.

$$
\begin{gathered}
\frac{\partial \phi_{i}}{\partial \beta}=\left(\frac{\xi-\varsigma_{i} \tau}{2(1-\beta-\lambda) \alpha r_{i} W_{i}}\right)^{3 / 2}\left(\frac{\alpha r_{i} W_{i}}{\xi-\varsigma_{i} \tau}\right)>0 \\
\frac{\partial^{2} \phi_{i}}{\partial \beta^{2}}=\frac{3}{2}\left(\frac{\xi-\varsigma_{i} \tau}{2(1-\beta-\lambda) \alpha r_{i} W_{i}}\right)^{5 / 2}\left(\frac{\alpha r_{i} W_{i}}{\xi-\varsigma_{i} \tau}\right)^{2}>0
\end{gathered}
$$

It can be seen from the above analysis that the game between the central and local governments on the collection of endowment insurance is mainly reflected by the collection income of endowment insurance, which is closely related to the collection intensity of local governments. At the same time, the local government's collection intensity is affected by the policy contribution rate, the payment base, the central pension adjustment ratio and the transfer payment from central government to local government etc.

Through equations (10) and (11), it can be concluded that there is a correlation between the collection intensity of local government and the central adjustment ratio in the collection of endowment insurance. The collection intensity of local endowment insurance rises with the increase of the adjustment proportion of central pension. The greater the proportion of adjustment, the greater the intensity of local collection. This shows that after the fee reduction, by raising the proportion of the central adjustment of the pension, the revenue of the central government and the local government can be increased simultaneously. By strengthening the collection management mechanism, the national pooling of the endowment insurance will be gradually implemented, and the vertical management of the endowment insurance is an effective management method to promote the collection of the endowment insurance. At the same time, it is also necessary to prevent raising the overall planning level too quickly, which may result in local government to reduce their enthusiasm for collection, and excessive relying on subsidies from central government, thus caused lazy politics and free-riding in the collection of endowment insurance premiums.

According to equation (6), it can be found that the local government's collection intensity has an inverse correlation with the contribution rate and contribution base. In the trend of declining contribution rates and contribution bases, local governments must strengthen collection management in order to prevent gaps in income and expenditure of endowment insurance funds and maintain the sustainability of endowment insurance funds. When the central government sets the contribution rate and the contribution base, in fact, there is no strong correlation between the local collection intensity and the indirect impact; the local government is more affected. At the same time, it can be found that the proportion of central government's transfer payments to local governments is affected by the minimum levy income, 
levy intensity, local government supervision costs, payment rates, and payment bases required by local governments to maintain the balance of endowment insurance funds. Only after local governments make efforts to collect and still have difficulty making up the gap, can they obtain more central transfer payments.

The central government has formulated a policy to reduce the contribution rate and adjust the contribution base after comprehensively considering economic development and the sustainable development of the endowment insurance fund. In order to effectively reduce the pension burden of enterprises while maintaining the sustainability of the endowment insurance fund, local governments must be strictly monitored Collection action. Promote the smooth adjustment of the endowment insurance contribution rate and contribution base by improving the overall level of endowment insurance, strengthening the management of transfer payments, and compensating provinces with low contribution rates. Because of the provincial-level co-ordination, local governments have a higher initiative in the collection of endowment insurance. During the collection process, there is a constant game between the payment subject and the subject of the payment. It is necessary to further analyze the behavior choices of local governments when collecting endowment insurance.

\section{Game between enterprises and local governments based on workers' Participation}

According to the social insurance law of the people's Republic of China, the object of collecting endowment insurance premium is workers and enterprises. Because workers work in enterprises in the form of employees, enterprises and local governments become the direct game subjects in the process of collecting endowment insurance, thus forming a tripartite game relationship among workers, enterprises and local governments. In the process of collection, due to the disunity of the management department and the actual charging Department of the collection of endowment insurance, the information held by all parties in the actual collection of endowment insurance is not complete. Under the condition of incomplete symmetrical information, all parties are limited rational in their behavior decisionmaking. Local governments, enterprises and workers pursue their own utility maximization, and constantly adjust the game policies among themselves Slightly so as to achieve a relatively stable state. In order to construct the game matrix and analyze the dynamic stable equilibrium, the decision-making parameters of local government, enterprises and workers are set as follows.

\section{Game parameter setting and hypothesis}

Hypothesis 1: from the perspective of local government departments, on the one hand, the government should actively collect funds according to the requirements of the central government to protect the pension rights and interests of the majority of workers; on the other hand, under the incentive of local economic development demand and tournament competition, local governments tend to violate regulations in order to attract FDI inflows. There are two strategies for local governments to choose in the collection of endowment insurance (strict supervision, weak supervision). According to the law, workers and enterprises should pay the endowment insurance fees in full according to the law, but in reality, in order to pursue short-term profits, enterprises pay the endowment insurance fees in arrears according to a lower payment base, or in violation of rules and regulations, and the behavior of endowment insurance evasion occurs from time to time. Workers can choose to work actively to create profits for the enterprise, or in order to get more leisure utility, they can choose to slack down and report the enterprise's behavior of evasion of arrears. Therefore, the action strategies of workers and enterprises in the process of collecting endowment insurance are as follows: (active work, slack work), (full payment, non-full payment). 
Hypothesis 2: After the fee reduction reform, when the company chooses to pay the old-age insurance premiums in full, the cost required is $Y_{1}$ (assuming that the company fully pays the old-age insurance premiums for its employees on time in accordance with the policy's payment rate and base); When paying the endowment insurance premiums, the expenses paid are $Y_{2}$ (the enterprise has tampered with the payment base without permission, underpaid in violation of regulations or deliberately delayed the non-payment of endowment insurance premiums for employees), which meets $Y_{1}>0, Y_{2} \geq 0, Y_{1}>Y_{2}$. If the fee reduction reform is implemented, the company will obtain a stable long-term income $L$ by paying the old-age insurance premiums in full, and the workers will receive the discounted value of the pension benefits of $P_{1}$ after retirement, and the workers will actively work to create income for the company in accordance with $\delta$ 's $(0<\delta<1)$ income coefficient. If after the fee reduction reform, the enterprise still chooses to pay the endowment insurance premiums in full, the company will receive short-term benefits $S$, and the discounted value of the pension benefits received by the workers after retirement will be $P_{2}$. At this time, in order to keep the workers motivated fund $D$ will be paid to compensate employees who work actively, and workers who receive fund subsidies will create revenue for the company according to $\varepsilon$ 's $(0<\varepsilon<1)$ profit coefficient. Meet $P_{1}>P_{2}, L>S+D$. The general wage income of workers in the course of work is $W$.

Hypothesis 3: After the enterprise pays the endowment insurance expenses in full, the workers still have the incentive to passively go idle. At this time, the penalty coefficient for the workers

will be $\varphi(0<\varphi<1)$ (the general company's approach is to deduct the proportion of wages).

When the enterprise pays in full, the workers have an incentive to report to the local government the company's endowment insurance expenses owed. At this time, in addition to the need to make up for the endowment insurance costs, the enterprise will also be subject to a certain penalty $F$. After the enterprise makes up the endowment insurance premium, the workers will be able to get sufficient pension treatment in the future.

Hypothesis 4: When the local government implements strict supervision to collect endowment insurance premiums, it needs to pay the cost $C$. If the company's arrears behavior can be accurately monitored, it will obtain a revenue $R$. If the local government adopts the strategy of weak supervision, but the workers report to the central government through petitions when the company evades the arrears, the local government will be punished by the central government for being lazy, and the penalty is $K$.

Hypothesis 5: After the fee reduction reform, the probability of workers choosing to work actively is $x(0 \leq x \leq 1)$, and the probability of slack work is $1-x$; the probability of enterprises choosing to pay endowment insurance premiums in full is $y(0 \leq y \leq 1)$, and the probability of paying the endowment insurance premiums in non-full is $1-y$; the probability of local government choosing strict supervision is $z(0 \leq z \leq 1)$, and the probability of weak supervision is $1-z$.

\section{Game returns matrix construction}

In order to simplify the game process, it is assumed that the company can accurately know whether the worker chooses to work actively based on the company's internal assessment. In 
the case of the establishment of a social insurance platform, the worker can learn his own endowment insurance payment situation through self-examination and other situations. However, in order to reduce workers costs, enterprises have falsely reported the company's payment base. In the case of cooperation between workers and enterprises, it has become more difficult for local governments to accurately collect enterprise endowment insurance. To implement the payment base of the enterprise, it is necessary to incorporate the selection of illegal payment by the enterprise into the game matrix. In summary, according to the parameter assumptions, the game return matrix of local governments, enterprises, and workers can be expressed as shown in Table 1.

Table 1 Game returns matrix of local government, enterprises and workers

\begin{tabular}{cccc}
\hline \multirow{2}{*}{ Game participants } & \multicolumn{2}{c}{ Local government } \\
\cline { 2 - 4 } & Workers active & strict supervision $z$ & weak supervision $1-z$ \\
\hline work & $x$ & $L-Y_{1}+\delta L$ & $P_{1}+W$ \\
Enterprise full & & $-C$ & $L-Y_{1}+\delta L$ \\
payment & Workers slack & $P_{1}+W-\varphi W$ & 0 \\
$y$ & work & $L-Y_{1}$ & $P_{1}+W-\varphi W$ \\
& $1-x$ & $-C$ & $L-Y_{1}$ \\
& Workers active & $P_{1}+W+D$ & 0 \\
work & $x$ & $Y_{2}-D+\varepsilon S-F$ & $P_{2}+W+D$ \\
Enterprise & & $-C+R$ & $S-Y_{2}-D+\varepsilon S$ \\
Non-full & Workers slack & $P_{1}+W$ & 0 \\
payment & work & $S-Y_{2}-F$ & $P_{1}+W$ \\
$1-y$ & $1-x$ & $-C+R$ & $S-Y_{2}-F$ \\
& & & $-K$ \\
& & &
\end{tabular}

\section{Evolutionary stability strategy analysis}

According to the above parameter hypothesis and the game income matrix, we can get the income function and the replication dynamic equation of each participant. For the replication dynamic equation, we can get the stable equilibrium strategy of each participant, establish the game strategy of each participant, construct the system Jacobian matrix, and get the relative stable equilibrium of the game matrix. Detailed analysis will be carried out below.

\section{Analysis of the evolutionary stability strategy of workers}

$U_{11}$ is the expected income of the workers' choice of active work, $U_{12}$ is the expected income of the workers' choice of slack work, and $\bar{U}_{1}$ is the average expected income of the workers' working attitude, specifically expressed as follows.

$$
\begin{gathered}
U_{11}=y z\left(P_{1}+W\right)+y(1-z)\left(P_{1}+W\right)+z(1-y)\left(P_{1}+W+D\right)+(1-y)(1-z)\left(P_{2}+W+D\right) \\
U_{12}=y z\left(P_{1}+W-\varphi W\right)+y(1-z)\left(P_{1}+W-\varphi W\right)+z(1-y)\left(P_{1}+W\right)+(1-y)(1-z)\left(P_{1}+W\right) \\
\bar{U}_{1}=x U_{11}+(1-x) U_{12}
\end{gathered}
$$

Therefore, the replication dynamic equation of workers choosing active work is as follows. 


$$
\begin{gathered}
F(x)=\frac{d x}{d t}=x(1-x)\left\{\left[\varphi W-\left(D+P_{2}-P_{1}-z P_{2}+z P_{1}\right)\right]+y\left(D+P_{2}-P_{1}-z P_{2}+z P_{1}\right)\right\} \\
F^{\prime}(x)=\frac{d^{2} x}{d t^{2}}=(1-2 x)\left\{\left[\varphi W-\left(D+P_{2}-P_{1}-z P_{2}+z P_{1}\right)\right]+y\left(D+P_{2}-P_{1}-z P_{2}+z P_{1}\right)\right\}
\end{gathered}
$$

Analyze the stability of the workers' replication dynamic equation, i.e. $F(x)=0$, we can get

$$
\text { get } x^{*}=0, x^{*}=1, y^{*}=\frac{D+P_{2}-P_{1}-z P_{2}+z P_{1}-\varphi W}{D+P_{2}-P_{1}-z P_{2}+z P_{1}} .
$$

Fig. 2 The evolutionary trend of the workers game strategy

(1) If $y \equiv \frac{D+P_{2}-P_{1}-z P_{2}+z P_{1}-\varphi W}{D+P_{2}-P_{1}-z P_{2}+z P_{1}}$, then $F(x)=0$ is satisfied, indicating that all horizontal states are stable, that is, all decisions of workers are in a stable state.

(2)If $y<\frac{D+P_{2}-P_{1}-z P_{2}+z P_{1}-\varphi W}{D+P_{2}-P_{1}-z P_{2}+z P_{1}}$, for $x^{*}=0$, exist $\left.F^{\prime}\left(x^{*}\right)\right|_{x^{*}=0}<0,\left.F^{\prime}\left(x^{*}\right)\right|_{x^{*}=1}>0$, then indicating that slack work is the only evolutionary stabilization strategy for workers.

(3)If $y>\frac{D+P_{2}-P_{1}-z P_{2}+z P_{1}-\varphi W}{D+P_{2}-P_{1}-z P_{2}+z P_{1}}$, for $x^{*}=1$, exist $\left.F^{\prime}\left(x^{*}\right)\right|_{x^{*}=0}>0,\left.F^{\prime}\left(x^{*}\right)\right|_{x^{*}=1}<0$,

indicating that active work is the only evolutionary stabilization strategy for workers.

The evolutionary trend of the workers game strategy is shown in Figure 2. When the initial game strategy chosen by the workers is $M_{1}, x^{*}=1$ is the evolutionary stable equilibrium point, that is, the workers is more willing to choose active work; when the initial strategy chosen by the workers is $M_{2}, x^{*}=0$ is the evolutionary stable equilibrium point, that is, the workers is more willing to choose slack work. The punishment degree and pension treatment of enterprises for workers' slack work are closely related to the choice space of workers' strategies. When the punishment is less, the workers are more inclined to do it; when the punishment is greater, they are more inclined to work actively. When the difference between the expected pension benefits of full payment and non-full payment is small, the working willingness of the workers is reduced, and they are more inclined to slack down; if the difference between the expected pension benefits of full payment and non-full payment is high, the workers are more willing to work actively. Enterprises can stimulate the enthusiasm of workers by paying the endowment insurance premium in full. 


\section{Analysis of the evolutionary stability strategy of enterprises}

$U_{21}$ represents the expected income of enterprises choosing to pay in full, $U_{22}$ represents the expected income of enterprises choosing not to pay in full, and $\bar{U}_{2}$ represents the average expected income of enterprises paying in full, specifically expressed as follows.

$$
\begin{gathered}
U_{21}=x z\left(L-Y_{1}+\delta L\right)+x(1-z)\left(L-Y_{1}+\delta L\right)+z(1-x)\left(L-Y_{1}\right)+(1-x)(1-z)\left(L-Y_{1}\right) \\
U_{22}=x z\left(S-Y_{2}-D+\varepsilon S-F\right)+x(1-z)\left(S-Y_{2}-D+\varepsilon S\right) \\
+z(1-x)\left(S-Y_{2}-F\right)+(1-x)(1-z)\left(S-Y_{2}-F\right) \\
\quad \bar{U}_{2}=y U_{21}+(1-y) U_{22}
\end{gathered}
$$

Therefore, the replication dynamic equation of enterprises choosing pay in full is as follows.

$$
\begin{aligned}
& F(y)=\frac{d y}{d t}=\mathrm{y}(1-y)\left[x(z F+\delta L+D-\varepsilon S-F)+\left(L-Y_{1}-S+Y_{2}+F\right)\right] \\
& F^{\prime}(y)=\frac{d^{2} y}{d t^{2}}=(1-2 y)\left[x(z F+\delta L+D-\varepsilon S-F)+\left(L-Y_{1}-S+Y_{2}+F\right)\right]
\end{aligned}
$$

Analyze the stability of the enterprise' replication dynamic equation, i.e. $F(y)=0$, we can

$$
\text { get } y^{*}=0, y^{*}=1, x^{*}=\frac{Y_{1}-Y_{2}-L+S-F}{z F+\delta L+D-\varepsilon S-F}
$$

(1) If $x \equiv \frac{Y_{1}-Y_{2}-L+S-F}{z F+\delta L+D-\varepsilon S-F}$, then $F(y) \equiv 0$ is satisfied, indicating that all horizontal states are stable, that is, all decisions of enterprises are in a stable state.

(2)If $x<\frac{Y_{1}-Y_{2}-L+S-F}{z F+\delta L+D-\varepsilon S-F}$, for $y^{*}=0$, exist $\left.F^{\prime}\left(y^{*}\right)\right|_{y^{*}=0}<0,\left.F^{\prime}\left(y^{*}\right)\right|_{y^{*}=1}>0$, then indicating that non-full payment of endowment insurance is the only evolutionary stability strategy for enterprises.

(3)If $x>\frac{Y_{1}-Y_{2}-L+S-F}{z F+\delta L+D-\varepsilon S-F}$, for $y^{*}=1$, exist $\left.F^{\prime}\left(y^{*}\right)\right|_{y^{*}=0}>0,\left.F^{\prime}\left(y^{*}\right)\right|_{y^{*}=1}<0$, then indicating that full payment of endowment insurance is the only evolutionary stability strategy for enterprises.

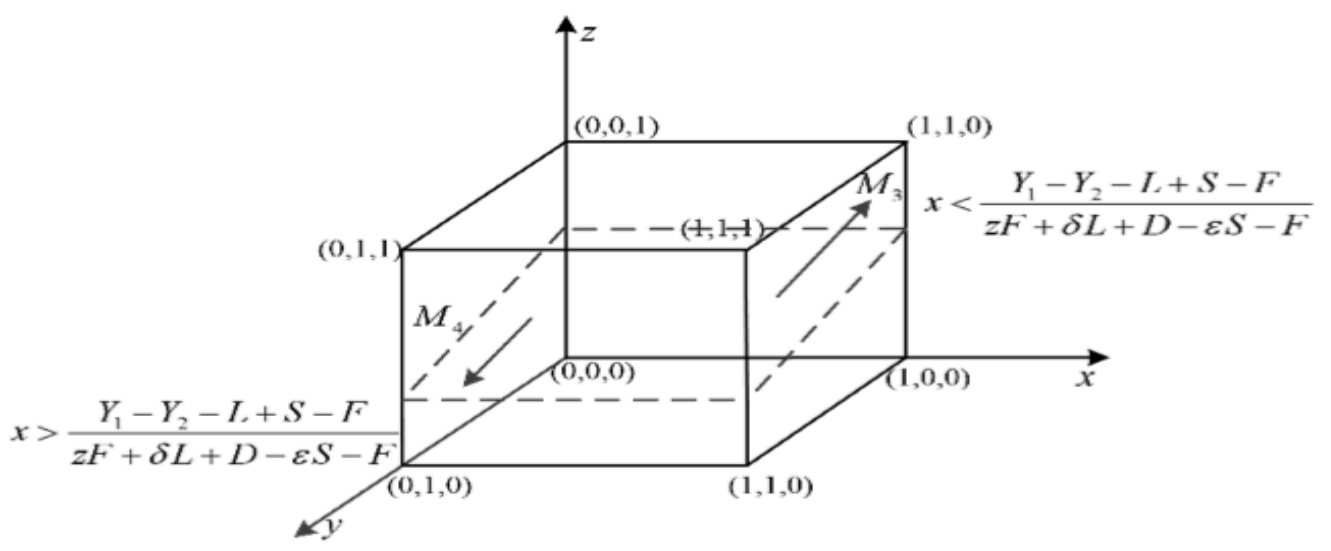

Fig. 3 The evolutionary trend of the enterprises game strategy

The evolutionary trend of the enterprise game strategy is shown in Figure 3. When the initial game strategy chosen by the enterprises is $M_{3}, y^{*}=1$ is the evolution stable equilibrium point, that is, the company is more willing to choose to pay the endowment insurance premium 
in full; when the initial strategy chosen by the company is $M_{4}, y^{*}=0$ is the equilibrium point of evolutionary stability, that is, enterprises are more willing to choose to pay endowment insurance premiums in full. The choice of corporate strategy is closely related to the penalties imposed by the local government on the enterprises, the benefits created by the collusion between the workers and the enterprises, and the illegal gains from corporate arrears. When the local government strengthens the supervision of enterprise endowment insurance collection, Enterprises will be encouraged to pay endowment insurance premiums in full. At the same time, the openness and transparency of endowment insurance collection will be actively enhanced to prevent collusion between workers and enterprises, and it will also promote full payment by enterprises.

\section{Analysis of the evolutionary stability strategy of local government}

$U_{31}$ represents the expected return of local governments choosing strict supervision, $U_{32}$ represents the expected return of local governments choosing weak supervision, $\bar{U}_{3}$ represents the average expected return of local government supervision, specifically expressed as follows.

$$
\begin{gathered}
U_{31}=x y(-C)+y(1-x)(-C)+x(1-y)(-C+R)+(1-x)(1-y)(-C+R) \\
U_{32}=x y * 0+y(1-x) * 0+x(1-y) * 0+(1-x)(1-y)(-K) \\
\bar{U}_{3}=z U_{31}+(1-z) U_{32}
\end{gathered}
$$

Therefore, the replication dynamic equation of local government choosing strict supervision is as follows.

$$
\begin{gathered}
F(z)=\frac{d z}{d t}=\mathrm{z}(1-z)[(R+K-K x-C)+y(R+K-K x)] \\
F^{\prime}(z)=\frac{d^{2} z}{d t^{2}}=(1-2 z)[(R+K-K x-C)+y(R+K-K x)]
\end{gathered}
$$

Analyze the stability of the local government' replication dynamic equation, i.e. $F(z)=0$, we

can get $z^{*}=0, z^{*}=1, y^{*}=\frac{K x+C-R-K}{R+K-K x}$

(1) If $y \equiv \frac{K x+C-R-K}{R+K-K x}$, then $F(z) \equiv 0$ is satisfied, indicating that all horizontal states are stable, that is, all decisions of local government are in a stable state.

(2) If $y<\frac{K x+C-R-K}{R+K-K x}$, for $z^{*}=0$, exist $\left.F^{\prime}\left(z^{*}\right)\right|_{z^{*}=0}<0,\left.\quad F^{\prime}\left(z^{*}\right)\right|_{z^{*}=1}>0$, then indicating that weak supervision is the only evolutionary stability strategy for local government.

(3) If $y>\frac{K x+C-R-K}{R+K-K x}$, for $z^{*}=1$, exist $\left.\quad F^{\prime}\left(z^{*}\right)\right|_{z^{*}=0}>0,\left.\quad F^{\prime}\left(z^{*}\right)\right|_{z^{*}=1}<0$, then 
indicating that strict supervision is the only evolutionary stability strategy for local government.

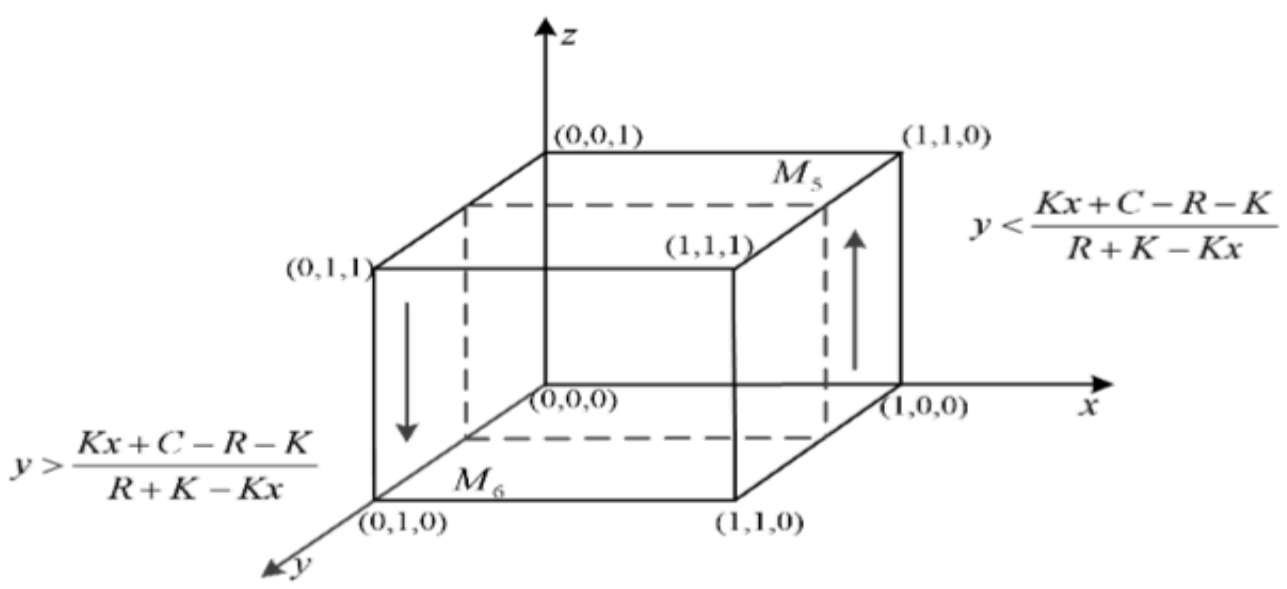

Fig. 4 The evolutionary trend of the local government game strategy

The evolutionary trend of the local government game strategy is shown in Figure 4 . When the initial game strategy chosen by the local government is $M_{5}, z^{*}=1$ is the evolutionary stable equilibrium point, that is, the local government is more willing to choose strict supervision; When the initial game strategy chosen by the local government is $M_{6}, z^{*}=0$ is the equilibrium point of evolutionary stability, that is, local governments are more willing to choose weak supervision. There is a strong correlation between the choice of local government strategy and the local government's regulatory costs and benefits, as well as the central government's punishment for local government violations. When strengthening local government's strict supervision, the central government's incentives and transfer payments to the local government can promote the local government to strengthen the supervision by improving the collection system, reducing the intermediate cost and reducing the supervision cost of endowment insurance collection.

\section{Equilibrium analysis of evolutionary stability in tripartite games}

As each subject continuously learns and adjusts its strategy in the game of the endowment insurance collection process, in order to determine the stable and equilibrium state of the three-party game, the simultaneous equations (15), (20), and (25) construct the simultaneous replication equation of the system as follows.

$$
\left\{\begin{array}{l}
F(x)=\frac{d x}{d t}=x(1-x)\left\{\left[\varphi W-\left(D+P_{2}-P_{1}-z P_{2}+z P_{1}\right)\right]+y\left(D+P_{2}-P_{1}-z P_{2}+z P_{1}\right)\right\} \\
F(y)=\frac{d y}{d t}=\mathrm{y}(1-y)\left[x(z F+\delta L+D-\varepsilon S-F)+\left(L-Y_{1}-S+Y_{2}+F\right)\right] \\
F(z)=\frac{d z}{d t}=\mathrm{z}(1-z)[(R+K-K x-C)+y(R+K-K x)]
\end{array}\right.
$$

Solving equation (27), we can obtain several equilibrium points in the game system, which are $(0,0,0),(1,0,0),(0,1,0),(0,0,1),(1,1,0),(1,0,1),(0,1,1),(1,1,1)$, and there is a general stable 
equilibrium point $\left(x^{*}, y^{*}, z^{*}\right)$. To judge the stability of these equilibrium points, according to

Friedman (1991), when $F\left(t^{*}\right)=0$ and $F^{\prime}\left(t^{*}\right)<0, t$ is the only evolutionary stability strategy (ESS). The system's Jacobian matrix needs to be constructed, and the stability of the equilibrium point can be obtained by solving the local stability of the Jacobian matrix. The Jacobian matrix of system is constructed as follows.

$$
J=\left[\begin{array}{ccc}
(1-2 x)\left\{\begin{array}{c}
{\left[\varphi W-\left(D+P_{2}-P_{1}-z P_{2}+z P_{1}\right)\right]} \\
+y\left(D+P_{2}-P_{1}-z P_{2}+z P_{1}\right)
\end{array}\right\} & \begin{array}{c}
x(1-x)\left[\varphi W-\left(D+P_{2}-P_{1}\right.\right. \\
\left.\left.-z P_{2}+z P_{1}\right)\right]
\end{array} \\
y(1-y)(z F+\delta L+D-\varepsilon S-F) & (1-2 y)[x(z F+\delta L+D-\varepsilon S & 0 \\
-K(1+y) z(1-z) & \left.-F)+\left(L-Y_{1}-S+Y_{2}+F\right)\right] & (1-2 z)[(R+K-K x \\
& z(1-z)(R+K-K x) & -C)+y(R+K-K x)]
\end{array}\right]
$$

According to observations, the matrix satisfies that the main diagonal product is greater than zero, and the main diagonal of the sub-matrix is less than zero. Therefore, a sub-matrix of the Jacobian matrix of the system can be obtained according to the properties of the matrix.

$$
J^{\prime}=\left[\begin{array}{cc}
(1-2 x)\left\{\begin{array}{c}
{\left[\varphi W-\left(D+P_{2}-P_{1}-z P_{2}+z P_{1}\right)\right]} \\
+y\left(D+P_{2}-P_{1}-z P_{2}+z P_{1}\right)
\end{array}\right\} & x(1-x)\left(D+P_{2}-P_{1}-z P_{2}+z P_{\nu}\right) \\
y(1-y)(z F+\delta L+D-\varepsilon S-F) & (1-2 y)[x(z F+\delta L+D-\varepsilon S-F) \\
& \left.+\left(L-Y_{1}-S+Y_{2}+F\right)\right]
\end{array}\right]
$$

A stable equilibrium of the system is achieved if and only if the determinant and trace of the matrix satisfy the following conditions.

$$
\left\{\begin{array}{l}
\operatorname{det}(J)<0 \\
\operatorname{det}\left(J^{\prime}\right)>0 \\
\operatorname{tr}\left(J^{\prime}\right)<0
\end{array}\right.
$$

The above represents the determinant of Jacobian matrix, the determinant and trace of

\begin{tabular}{|c|c|c|c|c|}
\hline $\begin{array}{c}\text { Equilibrium } \\
\text { point }\end{array}$ & $\operatorname{det}(J)$ & $\operatorname{det}\left(J^{\prime}\right)$ & $\operatorname{tr}\left(J^{\prime}\right)$ & Judge \\
\hline$(0,0,0)$ & -- & - & - & $\begin{array}{c}\text { Instability } \\
\text { point }\end{array}$ \\
\hline$(0,0,1)$ & $<0$ & $<0$ & $<0$ & $\begin{array}{l}\text { Instability } \\
\text { point }\end{array}$ \\
\hline$(0,1,0)$ & - - & $<0$ & - & $\begin{array}{c}\text { Instability } \\
\text { point }\end{array}$ \\
\hline$(1,0,0)$ & -— & - - & -— & $\begin{array}{c}\text { Instability } \\
\text { point }\end{array}$ \\
\hline$(0,1,1)$ & -— & $<0$ & -二 & $\begin{array}{l}\text { Instability } \\
\text { point }\end{array}$ \\
\hline$(1,0,1)$ & - & -— & - - & $\begin{array}{l}\text { Instability } \\
\text { point }\end{array}$ \\
\hline$(0,0,1)$ & - & - & -— & $\begin{array}{l}\text { Instability } \\
\text { point }\end{array}$ \\
\hline$(1,1,0)$ & $<0$ & $>0$ & $<0$ & Saddle point \\
\hline
\end{tabular}
submatrix. Thus, the equilibrium stable point state of the system is as follows:

Table 2 stability judgment of each equilibrium point 
It can be seen from Table 2 that $(1,1,0)$ is the instability point of the system, that is, the ideal state is that the workers are actively working, the enterprise pays the endowment insurance fees in full, and the local government chooses weak supervision, but in reality, the collection of endowment insurance still requires strict corporate supervision from enterprises. When $Y_{1}-Y_{2}-F<(1+\delta) L+D-(1+\varepsilon) S$ and $C<2 R$ are satisfied, $(1,1,1)$ becomes the stable equilibrium point of the system. That is, when the cost of local government supervision is less than the revenue earned by supervision, and the long-term benefits obtained from enterprises' full payment are more than the short-term benefits from enterprises' non-full payment, the evolution equilibrium of the three parties will eventually tend to (active work, full payment, strict supervision). We can see that in the tripartite game of local governments, enterprises, and workers, the punishment of workers' slack work, the return of enterprises' full payment and the revenue from government supervision affect the tripartite game equilibrium.

\section{Game among central government, local government, enterprises and workers}

The principal-agent game between the central government and the local government, and the tripartite evolutionary game between the local government and the workers and the enterprises provide a theoretical basis for the analysis of the behavior decision-making of each subject in the process of collecting endowment insurance. According to the above two kinds of game analysis, we can draw the main relations of the four sides as follows.

(1) The relationship between the central government and enterprise workers is mainly reflected by the amount of central transfer payment. In the context of cost reduction, the transfer payment from the central government to the local government affects the intensity of local government's levy on enterprises and workers. When the central government makes more efforts to transfer payment to local governments, the financial burden of local governments will be reduced, which will be more likely to accelerate the implementation of reducing the payment rate and payment burden, reducing the payment burden of enterprises and individuals. The transfer payment from the central government to the local government can be reflected by the collection intensity of the local government, that is, whether the supervision intensity chosen by the local government is strong or weak.

(2) The transfer payment from the central government to the local government also affects the decision-making of enterprises and workers. When enterprises and workers learn that the central government has increased its efforts to transfer to local areas, it will enhance the trust in the sustainability of endowment insurance and increase the enthusiasm of enterprises to pay in full. Workers are more willing to choose active work to obtain higher labor remuneration after their life is guaranteed.

To sum up, the key point of the game between the four sides is the strength of local collection, that is, local governments choose strong supervision and weak supervision.

\section{SIMULATION EXPERIMENT}

The local pension increase ratio is also closely related to the local government's collection intensity, which can be reflected indirectly through the collection intensity. Therefore, in the simulation experiment, the supervision of the local government was used to indirectly express the game relationship between the central government and the local government, and MATLAB software was used to numerically simulate the game relationship in the endowment insurance collection process. According to the analysis above, the local government's supervision 
intensity directly affects the stability and equilibrium of the system. Therefore, under the condition of satisfying the hypothesis of the equation of the text, other parameters of the system are randomly set, and the supervision intensity is given different values, and. From this, we can draw the evolutionary equilibrium game diagrams of local governments, workers, and enterprises in the process of collecting endowment insurance under different supervision intensities, as shown in Figures 5 and 6.

It can be seen from Figure 2 that when local governments choose weak supervision, over time, the effect of controlling workers' active work is greater than the effect of passive idle work, and the long-term profits of enterprises paying full endowment insurance costs are more than The short-term gain obtained when speculative non-full payment is made. At this time, the evolutionary stability point of the system is $(1,1,0)$, and the evolutionary stability strategy is (active work, full payment, weak supervision).

It can be seen from Figure 3 that when the local government chooses a strong regulatory strategy, paying the full endowment insurance fee in full can give workers a higher expected pension benefit, and they can also get a longer income for the company. The benefits of central transfer payments and local government supervision obtained from strong supervision will be higher. At this time, the evolutionary stability point of the system is $(1,1,1)$, and the evolutionary stability strategy is (active work, full payment, strong supervision).

Figure 5 Equilibrium of evolutionary game among workers, enterprises, and local governments under weak supervision of the central government

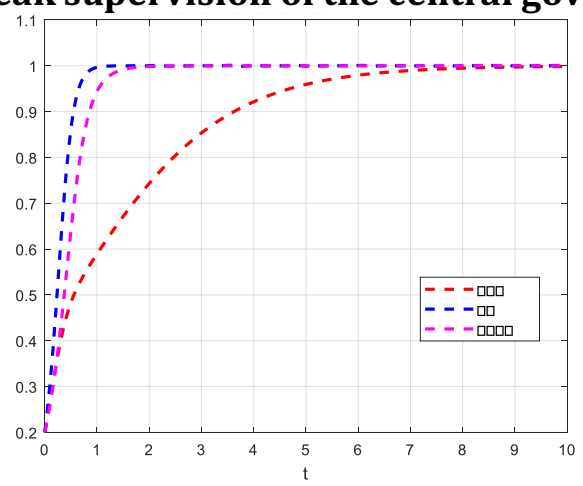

Figure 6 Equilibrium of evolutionary game of laborers, enterprises, and local governments under strict supervision of the central government

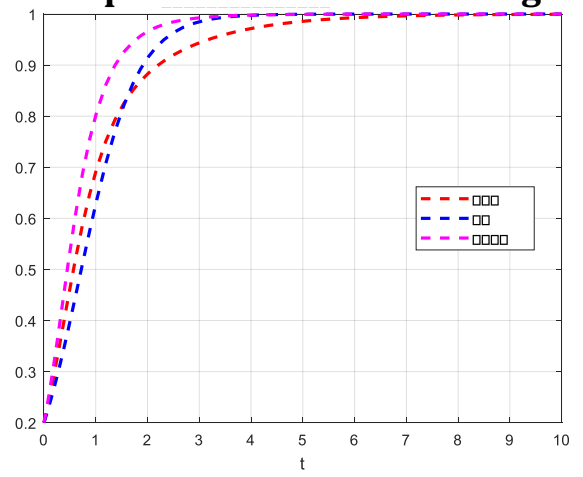

\section{CONCLUSION}

The reduction of the endowment insurance contribution rate and the adjustment of the payment base have shifted the pressure of endowment insurance benefits to the central and local governments themselves. In order to continue the sustainability of the endowment insurance fund, increasing the endowment insurance revenue at this time is an urgent issue 
important question. As the key subject of endowment insurance collection, local governments must play a two-party game with the central government and a three-party game with enterprise workers. It is against this background that this article analyzes the behavioral decisions of various subjects in the process of endowment insurance collection. First consider the principal-agent relationship between the central government and local governments in the formulation of the collection policy. Second, in the endowment insurance collection process, add workers to the game between enterprises and local governments in the collection of endowment insurance, and use evolutionary games. Based on the analysis of the decisionmaking behavior change trend and action direction of each subject, the dynamic equation of replication is used to demonstrate the equilibrium of the tripartite game. It can be found from the analysis results that the behaviors of the three parties in the game affect each other, and the three are closely related. The results show that: (1) The central government, as the coordinating subject in the operation of endowment insurance, has played an important role in promoting the collection of endowment insurance revenue by its management of local government levies. The level of local government levy income is on the rise with the central government 's pension adjustment ratio and the degree of local supervision. Therefore, the central government needs to fully consider the economic development and pension collection of each province, autonomous region and municipality, and gradually increase the level of overall planning. . To properly handle the relationship between the central and the local governments, we must control the bottom-to-bottom competition between endowment insurance collections for GDP among local governments, and prevent free-riders in some provinces. (2) According to the evolutionary game results, it can be seen that the pension benefits obtained by workers can promote the workers to work actively and at the same time prompt the enterprises to change the endowment insurance premiums in full. Therefore, the establishment of a personal pension account by some scholars has promoted the evolution of the decision-making of each subject in a beneficial direction. That is, the evolutionary game equilibrium solution is gradually working towards the workers, the enterprise pays the endowment insurance expenses in full in accordance with regulations, and the local government actively strengthens the regulatory evolution in the endowment insurance collection process. (3) Through analysis, it can be found that increasing supervision is the key point to promote the collection of endowment insurance income. This is reflected not only in the central government's need to strengthen supervision of local governments, but also in the local government's need to strengthen supervision of enterprises. However, there are some critical points in the penalties imposed by enterprises on workers, which may be because the penalties make workers work more passively.

Therefore, in order to achieve a reduction in the overall level of levy income and the sustainability of endowment insurance funds in the context of fee reduction, local governments need to expand the coverage of endowment insurance, increase the compliance rate of endowment insurance, and increase the intensity of levy. Contribution base to improve the level of collection of endowment insurance. The central government should gradually increase the level of the endowment insurance, promote the perfection and unification of the endowment insurance collection system, improve the mechanism for the collection of endowment insurance costs by the tax department, promote the further improvement of the social insurance public service platform, and establish a channel for public reporting.

\section{Reference}

Liu Junqiang. Resources, Incentives and Departmental Benefits: A Cross-Sectional Study of China's Social Insurance Levy System (1999-2008) [J]. China Social Sciences, 2011 (03): 139-156 + 223. 
Qi Chuanjun. Prediction of Pension Gap After Reduction of Endowment Insurance Fees and Measures in the Middle and Long Term [J]. Journal of Huazhong University of Science and Technology (Social Science Edition), 2019, 33 (03): 19-25.

Yang Cuiying, Wang Runquan, Cheng Yu. Rate level and rate structure: International comparison of social insurance contributions [J]. Economic System Reform, 2018 (02): 152-158.

Feng Jin. Participation Incentive of Social Insurance System for Chinese Urban Employees [J]. Economic Research, 2013, 48 (07): 104-117.

Zheng Bingwen. Lowering the contribution rate and expanding personal accounts of endowment insurance-the "extra gain" of reform of the levy system [J]. Administrative Reform, 2018 (11): 12-21.

Zeng Yi, Li Xiaolin. Reducing pension insurance contribution rate and fund sustainability: can fish and bear's paw have both? [J]. Journal of Shanghai University of Finance and Economics, 2019, 21 (04): 100-111.

Zeng Yi, Li Xiaolin, Shi Chenxi. How far can the policy of reducing the endowment insurance contribution rate go? [J]. Finance Research, 2019 (06): 102-115.

Chen Xi. Endowment insurance fee reduction rate, fund income and long-term income and expenditure balance [J]. China Population Science, 2017 (03): 55-69 + 127.

Yang Jun.Study on the Optimal Contribution Rate of the Endowment Insurance System of "Combined Accounts" [J]. Social Security Review, 2017,1 (03): 57-69.

Zheng Bingwen. Supply-side: Significance of fee reduction to structural reform of social insurance [J]. China Population Science, 2016 (03): 2-11 + 126.

Yang Lixiong. Research on countermeasures to strengthen the management of endowment insurance levy [J]. Economic Survey, 2010 (09): 33-37.

Wang Runquan, Jin Hao, Yang Cuiying. Is China's Social Insurance Burden High or Low? - - An Empirical Analysis Based on Actual Payments of Enterprises and Employees [J]. Journal of Jiangxi University of Finance and Economics, 2017 (06): 53-63.

Cheng Xin, Deng Dasong. An empirical analysis of the actual social insurance payment rate standards for Chinese enterprises [J]. Statistics and Decision, 2019, 35 (03): 185-188.

Zhao Jing, Mao Jie, Zhang Lei. Social Insurance Contribution Rate, Participation Probability, and Contribution Level: An Empirical Study on Evasion Behavior of Employees and Enterprises [J] .Economics (Quarterly), 2016, 15 (01) : 341-372.

Zheng Bingwen. Significant "double drop": a turning point in the process of social security reform: from the perspective of long-term institutional arrangements and long-term economic growth [J]. Journal of Huazhong University of Science and Technology (Social Science Edition), 2019, 33 (03 ): 1-10.

Hu Qiuming, Jing Peng. Evolution and adjustment of the relationship between social insurance payment subject's evasion behavior [J]. Science of Finance and Economics, 2014 (10): 19-28.

Enoff, L. D.\& McKinnon, R. (2011). Social Security Contribution Collection and Compliance: Improving Governance to Extend Social Protection. International Social Security Review, 64 (4) :99-119.

Bailey, C. \& Turner, J. (2001). Strategies to Reduce Contribution Evasion in Social Security Fnancing. World Development, 29(2): 385-393.

Warren McGillivray. Contribution evasion: Implications for social security pension schemes[J]. International Social Security Review,2001,54(4).

Wang Xianhe, Song Zhijiang, Ma Yuxiang. Efficiency Analysis and Reform Path Choice of Social Insurance Fee Collection and Management Model in China [J]. Tax Research, 2014 (05): 74-77.

Tine Stanovnik,Predrag Bejaković,Agnieszka Chłoń-Domińczak. The collection of pension contributions: a comparative review of three Central European countries[J]. Economic Research-Ekonomska Istraživanja,2015,28(1).

Peng Xuemei, Liu Yang, Lin Hui. Will the collection agency affect the collection effect of social insurance premiums? - - An empirical study based on the effect of social security agency and local tax collection [J]. Management World, 2015 (06): 63 -71.

Jiang Hongli, He Jianmin, Yao Hongxing. Evolutionary Game Analysis of "Evasion of Fees" in the Collection of Social Endowment Insurance [J]. Statistics and Decision, 2017 (04): 161-163. 
Peng Haoran, Yue Jinglun, Li Chenhuan. Is there a bottom-to-bottom competition in the collection of endowment insurance by Chinese local governments? [J]. Management World, 2018, 34 (02): 103-111.

Peng Zhaiwen. Fiscal Decentralization, Transfer Payments and Incentives for Local Government Endowment Insurance Evasion Management [J]. Social Security Research, 2010 (01): 138-150.

Gillion, C., Turner, J., Bailey, C. \& Latulippe, D. Eds. (2000). Social Security Pensions: Development and Reform. Geneva: International Labor Office.

Duan Yawei. Motivation of enterprises, employees and the government conspiring to evade insurance-based on a three-party game model [J]. Journal of Jiangxi University of Finance and Economics, 2015 (02): 59-68.

Zhao Man. Transfer burden and fragility of China's endowment insurance system [J]. Economic Management, 2010, 32 (12): 151-157.

Meng Rongfang. Finding balance in the game of interests: a logic analysis of the decision of the local government's basic old-age security system [J]. Economics and Management, 2014, 28 (04): 21-27.

Zeng Yi, Ling Yun. The space and scheme simulation of the reduction of China's social insurance contribution rate: A case study of the basic endowment insurance for urban enterprise employees [J]. Finance and Economics Journal, 2017 (06): 50-59.

Zhang Rui, Liu Junxia. Study on the Spatial Reduction of Employees' Basic Pension Insurance Contribution Rate—Based on Provincial Panel Data [J]. Economic Survey, 2018, 35 (01): 138-145.

Li Pei, Fan Chuan. Study on the Adjustment Space of China's Urban Employee Endowment Insurance Rates [J]. Insurance Research, 2018 (01): 14-26.

Yang Jun. Research on the Optimal Contribution Rate of the Endowment Insurance System of "Combined Accounts" [J]. Social Security Review, 2017, 1 (03): 57-69.

Yang Zaigui. Research on the Optimal Contribution Rate and the Best Bookkeeping Interest Rate of Basic Endowment Insurance for Enterprise Employees at the Present Stage [J]. Journal of Huazhong Normal University (Humanities and Social Sciences), 2018, 57 (01): 55-64.

Wang Runquan, Lu Yu, Yang Cuiying. How is it possible to reduce pension insurance fees? - — Actuarial analysis from the perspective of fund balance [J]. Population and Development, 2019, 25 (04): 23-33.

Hong Li, Zeng Guoan. Adjustment of Endowment Insurance Contribution Rate and Economic Growth: Theoretical Model and Numerical Simulation [J] .Social Security Research, 2017 (02): 3-12.

Ouyang Ying, Zhou Xingying. Game Analysis of Evolution of Corporate Taxation Based on "Whistler" [J] .Tax Research, 2019 (03): 86-90.

Peng Minjiao, Fang Zhu, Wang Min. Research on the Behavior of Tax Collection Subjects from the Perspective of Game Theory [J] .Tax Research, 2019 (08): 89-97.

Li Chungen, Xia Yi. The formation logic, essence and policy adjustment of corporate social insurance payment bases: based on the perspective of collective selection of stakeholders [J]. Tax Research, 2019 (06): 10-15.

Friedman D. Evolutionary games in economics[J]. Econometrica, 1991,59(3):637-666.

Chen Zhenling, Wang Wenju. Game analysis of the evolution of government and polluting enterprises under the environmental tax system [J]. Management Review, 2017, 29 (05): 226-236.

Zhou Feizhou. Tournament System [J] .Sociology Research, 2009,24 (03): 54-77 + 244.

Song Biao, Xu Shasha, Ding Qingyang. Game Analysis of the Evolution of Opportunistic Behaviors of Enterprise Cooperation and Government Supervision under the "Belt and Road" Strategy [J]. Management Review, 2018, 30 (01): 118-126. 